\title{
Discussion on the Binding Model of WeChat-Assisted PBL and Formative Evaluation in English Teaching for Medical International Students
}

\author{
Yan Li, Qichuan Huang, Xiufeng Huang, Yan-E Zhou, Qianli Tang*, Xianjiu Liao* \\ Youjiang Medical University for Nationalities, Baise, China \\ Email: *htmgx919@163.com, *lxj2006910@163.com
}

How to cite this paper: Li, Y., Huang, Q. C., Huang, X. F., Zhou, Y.-E, Tang, Q. L., \& Liao, X. J. (2020). Discussion on the Binding Model of WeChat-Assisted PBL and Formative Evaluation in English Teaching for Medical International Students. Creative Education, 11, 1795-1801.

https://doi.org/10.4236/ce.2020.119131

Received: September 3, 2020

Accepted: September 21, 2020

Published: September 24, 2020

Copyright $\odot 2020$ by author(s) and Scientific Research Publishing Inc. This work is licensed under the Creative Commons Attribution International License (CC BY 4.0).

http://creativecommons.org/licenses/by/4.0/

\begin{abstract}
Due to the difficulty in the quantitative evaluation of the learning behavior of international students, formative evaluation has always represented a challenge for instructors in medical colleges. In the era of "Internet plus Education", teachers could utilize the WeChat platform, to capitalize upon the supporting and leading function of information technology, to build the binding teaching mode of WeChat-assisted PBL and formative evaluation, and to carry out the real-time tracking, recording and feedback of the growth process of international students. This kind of teaching mode could realize more overall and fair quantitative evaluation and promote the transformation of international students from "passive learning" to "active learning". WeChat could help address the current challenges of formative evaluation to a great extent with piles of powerful functions. This paper would probe into the binding teaching mode of WeChat-based PBL and formative evaluation, to establish the learner-centered and OTO (Online to Offline) educational ecology for international students. It is expected to provide some reference for the teaching reform of "Internet plus Education" Mode in our country.
\end{abstract}

\section{Keywords}

PBL, WeChat, Formative Evaluation, International Students, Medical Universities, Internet plus Education

\section{Introduction}

As mentioned in the "Internet plus Education" Action Plan of Guangxi Province (2018-2022), committed to the core ideology of in-depth integration of informa- 
tion technology, education and teaching, we shall give full play to the supporting and leading role of information technology, to realize the fair and high-quality education, to promote the all-round development of students, and to activate the "Internet plus Education" platform. We also need to carry out education and teaching by utilizing the space, and unfold the data-based education and teaching and comprehensive quality assessment of students. Besides, we shall guide teachers to use space to implement several new modes, such as project teaching and blended teaching, to carry out study evaluation and problem diagnosis, and to conduct differentiated and personalized teaching and instruction. We must guide students to use space to take part in teaching activities in or out of class, to record their growing process, to manage and present their learning results, and to record the process data of comprehensive quality assessment. Hence, it is of great practical significance to conduct scientific and effective formative assessment of international students' learning with WeChat and other platform data.

Education of international students stands for a vital part of higher medical education in China, which shall emphasize not only the teaching of the theoretical knowledge system, but also the training of experimental skills. International students are greatly influenced by western civilization, with learning concepts and personalities quite different from those of Chinese students, which therefore leads to some international students not adapting to the traditional teaching and evaluation methods, then affecting the teaching efficiency (Huang, 2020). For a long time, our college has been employing the summative evaluation for the teaching evaluation of international students. In order to pass it, international students have to depend on rote memorization of knowledge points, which ultimately attach importance to the teaching results and neglect the learning process, and cannot well reflect the students' capabilities of mastering and applying knowledge. As a result, the establishment of a more scientific and reasonable teaching mode and assessment system plays a great role in deepening the teaching reform of international students and enhancing the teaching quality (Xia, Sun, Hu, Zhao, Han, \& Sun, 2019). This paper would take the combined teaching mode of WeChat-assisted PBL teaching and formative evaluation as an example, to explore the teaching mode of "Internet plus Education" and the OTO educational ecology based on WeChat, hoping to provide some reference for the teaching reform of "Internet plus Education" Mode in China.

\section{WeChat-Assisted PBL and Formative Evaluation}

For a long time, the summative evaluation has accounted for a significant proportion in the education system for international students in our school. Teachers often get the picture of the students' learning effect mainly through the final examination, the main disadvantage of which represents the negligence of the whole process of students' learning and emphasis of evaluation of learning results, resulting in the absence and halfheartedness of some international student. Short of examination of the students' learning process, summative evaluation 
cannot fully reflect students' learning effect, adverse to stirring up students' enthusiasm for learning at ordinary times. Formative evaluation refers to the assessment of students' performance, achievements and the development of emotions, attitudes and strategies reflected in their daily study process, and the in-time feedback of results to teachers and students, conducive to encouraging students to learn and helping students to regulate their learning process in time (Wang, Gong, Zhu, Yang, Gao, He, Lin, \& Bu, 2020). Formative evaluation could reflect the learning conditions of international students more objectively and comprehensively, help them to acquire a sense of achievement, functioning as a crucial role in cultivating and boosting their ability to think and actively acquire knowledge.

PBL stands for the problem-oriented teaching method, which could facilitate the construction of the clinical knowledge system, and the cultivation of effective clinical thinking and critical thinking of students through situational teaching and discussion teaching; It could also improve students' capacities of independent learning and thinking, accordingly cultivating students' lifelong learning ability (Li, Ning, Meng, Hu, \& Zhu, 2020). The integration of formative evaluation and PBL teaching for international students is favorable for timely evaluating the teaching effect of PBL and the learning process of international students, which could develop the subjective initiative of international students. The teaching method of formative evaluation combined with PBL is clinically aimed and student-centered, and it reflects the educational philosophy that teaching benefits teachers as well as students, which is helpful to stimulate international students' interest and initiative in learning and cultivate their self-learning ability.

The introduction of formative evaluation has invigorated the education and teaching of international students. However, the implementation of formative evaluation signifies repeatedly carrying out various assessment activities, which would augment the workload of teachers. Due to the lack of real-time data collection methods and technical support, the implementation of formative evaluation is beset with difficulties. Under the context of "Internet plus Education", education has gradually become a constituent of the Mobile Internet era. WeChat Platform, as a real-time interaction and communication platform, can perform the real-time tracking and record data, which provides a technical support as the solution to the puzzle, thereby making the formative evaluation of mobile learning possible (Gao, Zheng, Zhang, Yan, Wei, Lyu, Ma, \& Qiu, 2019).

\section{Advantages of the Implementation of PBL Teaching and Formative Evaluation with WeChat}

In the current context where the medical colleges are large in scale and massive in enrollment, the theory teaching is mainly done in large classes. Since formative evaluation increases the teachers' workload, it is difficult to carry out in large classes. Especially for teachers of clinical disciplines in some medical col- 
leges, they are engaged in not only the clinical work, but also the teaching work, which makes teachers too overwhelmed to take formative evaluation into account. For want of information technology, there exists a heavy workload in formative evaluation, which means the challenges of realizing formative evaluation on a larger scale for international students in our school.

WeChat, as a mobile social networking software and a widely used real-time communication means in China, has become a universal communication tool among international students. WeChat, as an auxiliary teaching platform for real-time interactional feedback, is featured by numerous powerful functions, such as quickly sending videos, pictures, text and voice, and group chat, etc., which could solve the current problems encountered in formative evaluation to a great extent (Zhang, Liu, Yang, \& Zhang, 2018). The application of mobile WeChat platform in the teaching reform of combined PBL teaching and formative evaluation of international students is characterized by: 1) Realize the sharing of learning resources and improve the independent learning effect of international students. It is very convenient and efficient to publish PBL case data, teaching plans, test questions, videos, web links and other forms of teaching resources on WeChat platform. 2) Strengthen teacher-student exchanges and student-student exchanges, and effectively monitor the learning process. If international students have any questions, they can ask teachers on WeChat at any time and they can also communicate with each other through WeChat. Teachers and students can use WeChat platform for course feedback. Teachers can collect feedback from international students through the mini program or the official account on the WeChat Official Accounts Platform, and provide individual guidance to international students. They can also collect feedback from students, find out the flaws and make them up purposefully, effectively monitor the learning process of international students and urge them to complete learning tasks on time to improve learning performance and grades; 3 ) Realize the real-time tracking, recording and feedback of the growth process of international students, and realize fair quantitative evaluation for them: Using the official accounts of WeChat Official Accounts Platform such as Duifene, Moso Tech, Sojump and so on, teachers can quantify and record every teaching activity and learning behavior that international students participate in by setting experience points. This quantitative evaluation is comprehensive and objective, which enhances the credibility and fairness of the evaluation, and at the same time makes students pay more attention to their usual study and develop good study habits; 4) Achieve the summary, statistics and analysis of big data. Taking Duifene, Moso Tech and other official accounts in WeChat Official Accounts Platform as examples, through the "Scorebook" of the Duifene platform, teachers can set the proportion of every online assignment score in the total score. At the end of the term, the total scores can be easily generated automatically. Teachers can set up more evaluation methods based on the actual situation by using the function of "Manage Custom Scores" of Duifene. In addition, by integrating the usual scores 
(experience points) and the final exam scores of Moso Tech through "Manage Custom Scores" function, the total scores can be automatically generated, which greatly improves the efficiency of teachers' work.

\section{Discussion on the Application of Teaching Mode Combining PBL and Formative Evaluation Based on WeChat}

1) Pre-class evaluation

Before class, teachers will send the prepared case materials in English, as well as PPT courseware, micro-class video learning resources to the international students through WeChat official accounts such as Duifene and Moso Tech. International students can communicate with teachers at any time through the WeChat platform, and the international students are divided into groups to discuss the cases individually. Teachers can send notifications through WeChat official account to remind international students to study and discuss before class. After receiving the notification, the international students can leave a message directly on the platform and get corresponding learning points. The platform will also automatically record the participation of students and make an objective and reasonable evaluation of their preview. Teachers can make targeted teaching plans according to the feedback from the discussion before class, laying a foundation for high-quality classroom teaching.

2) In-class evaluation

Classroom evaluation mainly includes attendance rate, classroom participation, interaction between teachers and students and so on. First of all, the check-in function of WeChat official account platforms such as Duifene and Moso Tech is used to assess the attendance of students. The whole process is simple and convenient, which saves the time for class roll call. The attendance can be checked at any time and the attendance results can be automatically generated through the data analysis function of the platform. Then it is the application of classroom performance function. The classroom performance of international students is the main basis and important content of formative evaluation. Classroom activities for international students include online quizzes and discussions, group reports, competitive answering, voting, etc. The platform will automatically record the participation of international students in classroom activities and make objective and reasonable evaluations.

3) After-class evaluation

When reviewing after class, international students can communicate and learn with teachers and other students through the WeChat official account anytime and anywhere. Teachers can also issue test questions through WeChat official accounts such as Duifene and Moso Tech, and stipulate the scores of the test questions. International students complete the test within the specified time after class. After the test, the system will automatically generate scores, and teachers can check the distribution of the scores of international students at any time. At 
the same time, teachers can conduct questionnaire surveys based on the teaching situation to understand the views of international students on the teaching mode, and optimize the teaching methods in time based on the feedback of students. The platform will automatically record the participation of international students in tests and questionnaire surveys, and make objective and reasonable evaluations based on their participation. The results of tests and questionnaires can be fed back in time, which helps teachers grasp the overall situation of classroom teaching and adjust teaching strategies. Thus, it is conducive to the continuous improvement of teachers' teaching level.

\section{Conclusion}

Under the "Internet plus Education" environment, online teaching, especially mobile information teaching, has emerged. Under the student-centered WeChat-assisted PBL teaching model, the traditional summative evaluation, which only focuses on the learning results, is difficult to evaluate some learning elements in the "Internet plus Education" teaching mode objectively and scientifically. The teaching method of formative evaluation combined with PBL is clinically aimed and student-centered, and it reflects the educational philosophy that teaching benefits teachers as well as students, which is helpful to stimulate students' interest and initiative in learning, cultivate students' self-learning ability, and promote the formation of clinical thinking. Using the WeChat platform to collect student learning information can help solve the current problems encountered in formative evaluation to a large extent, realize real-time tracking, recording and feedback of the growth process of international students, and provide comprehensive and multi-angle quantitative evaluation to them. Recording and tracking the progress of foreign students at all times can not only reflect the teaching effect objectively, but also continuously supervise them in teaching, improve their learning enthusiasm and self-learning ability, and can also improve the efficiency teaching foreign students. This teaching mode is in line with international teaching methods and is more suitable for international students.

\section{Fund Program}

Subject of Guangxi Educational Science in the $13^{\text {th }}$ Five-year Planning + "Research on the Application of WeChat Supported PBL in English Teaching of Elementary Medical Chemistry for International Medical Students" + (2017C403).

\section{Conflicts of Interest}

The authors declare no conflicts of interest regarding the publication of this paper.

\section{References}

Gao, Y., Zheng, J. P., Zhang, W. P., Yan, X. Y., Wei, C. L., Lyu, Y., Ma, X. X., \& Qiu, Y. L. 
(2019). Using Formative Assessment via WeChat \& Sojump in the Teaching of Toxicology. China Higher Medical Education, No. 9, 52-53.

Huang, R. Y. (2020). A Case Study on the Situation and Trend of Undergraduate Medical Education for International Students. Medical Education Research and Practice, 28, 621-624+640.

Li, Y. H., Ning, C. H., Meng, C. R., Hu, Z. F., \& Zhu, Y. S. (2020). Discussion on Improving the Teaching Quality of Overseas Students in China by WeChat and PBL. China Continuing Medical Education, 12, 15-17.

Wang, P., Gong, L., Zhu, X. L., Yang, J. K., Gao, J. G., He, J., Lin, A. Q., \& Bu, W. J. (2020). The Practical Exploration of Formative Evaluation Based on Rain Classroom Teaching Model in Medical Genetics Teaching. Journal of Youjiang Medical University for Nationalities, 42, 385-388+391.

Xia, X. X., Sun, L. Q., Hu, S., Zhao, J., Han, P. P., \& Sun, Y. (2019). The Application of Achievement Assessment Model of Formative Assessment Combined with Summative Assessment in the Teaching of Traditional Chinese Medicine for Foreign Students. Chinese Medicine Modern Distance Education of China, 17, 32-35.

Zhang, F. F., Liu, W. N., Yang, C. C., \& Zhang, S. H. (2018). The Application of Network Platform in the Formative Appraisement in the Teaching of Surgery. China Continuing Medical Education, 10, 41-43. 